\title{
$\bullet$ Health Care Delivery in Malaysia as Perceived by Bangladeshi Migrant Workers
}

\section{IJCRR}

Section: Healthcare ISI Impact Factor (2019-20): 1.628

IC Value (2019): 90.81 $\operatorname{SJIF}(2020)=7.893$

\section{Md Mizanur Rahman, Mohamad Taha Arif, Razitasham safii, Zainab Tambi, Cliffton Akoi, Zulkifli Jantan, Kaliaperumal, Saiful Ridzuan}

Faculty of Medicine and Health Sciences, Universiti Malaysia Sarawak, Malaysia.

\section{ABSTRACT}

Background: Perception of health care delivery affects the utilisation of the services by the recipients.

Objective: This study attempted to assess Malaysia's health care delivery perceived by Bangladeshi workers in Sarawak, Malaysia.

Methods: A structured Likert scale questionnaire was used to assess health care delivery perception in Malaysia. A total of 314 data were collected from Bangladeshi workers through face-to-face interviews in a cross-sectional study design. A stepwise multiple linear regression analysis was done to determine the perceived accessibility, affordability, and equity in health delivery. IBM SPSS version 22.0 was used for data entry and analysis.

Results: The healthcare delivery was assessed by three domains viz. accessibility, affordability, and equity of care. A stepwise forward and backwards multiple linear regression analysis found that daily wage payment $(p<.001)$, monthly income MYR 900$1300(p<.001)$, and income MYR $\geq 1300(p<.001)$ are strongly positively correlated with perceived health care. While factors, namely, manufacturing jobs, having no idea about health insurance, and adaptation of local culture, are negatively correlated with perceived health care $(p<.05)$. The field note analysis revealed a mixed feeling of health care services in Malaysia by migrant workers.

Conclusion: This study's findings would be necessary to develop a migrant worker's friendly health care delivery policy in the country, which is affordable and equitable. The study could also be replicated in other migrant workers to examine and inform migrant health research.

Key Words: Accessibility, Afordability, Bangladesh, Equity, Malaysia, Migrant workers, Perception, Sarawak

\section{INTRODUCTION}

Since 1957, the Malaysian health care system had evolved from prescribing essential traditional remedies to providing world-class health care services. ${ }^{1}$ In 1978 after the Alma Ata declaration, the government, through the Ministry of Health $(\mathrm{MOH})$, has been reorganising its services. ${ }^{2}$ The health care system of a country is designed to cater to populations' needs and a complete curative model. As time goes, the health care system faces new changes. From a doctor-illness focused era, the system stepped into more preventive care with a healthier lifestyle and risk prevention techniques. ${ }^{3}$ Health services covered all aspects of comprehensive health care, including preventive, promotive, curative, and rehabilitative care. ${ }^{4}$ The Ministry of Health leads the health care services in Malaysia.
The public healthcare system is heavily subsidised by the government, thus providing many affordable and comprehensive health care services to the public. ${ }^{3}$ The second major providers are private sectors. ${ }^{4,5}$ The services provided in the private sectors are the same as what the government sectors are providing, but the users pay all the cost for the services. The services are thus only for the community who can afford such luxury. ${ }^{6}$ Foreign workers, similarly, can patronise either private or public health care services. However, foreign workers are obliged to pay an equal amount of money in public and private health care centres. ${ }^{7}$ Agents of such workers are requested to provide private health insurance that covers hospitalisation and surgical charges at public hospitals. If the foreign individuals choose to patronise service in private centres, the cost is to be borne from their own pockets.

\section{Corresponding Author:}

Md Mizanur Rahman, Faculty of Medicine and Health Sciences, Universiti Malaysia Sarawak, Malaysia. Email:rmmizanur@unimas.my

ISSN: 2231-2196 (Print)

ISSN: 0975-5241 (Online)

Received: 05.10 .2020

Revised: 02.11 .2020

Accepted: 04.12.2020

Published: 23.02 .2021 
Migrant workers are always seen as a vulnerable population, especially for adequate health care. ${ }^{7}$ The factors that may affect the vulnerability include socioeconomic condition, language proficiency, federal, state, and local policies on access to public-funded health care, accommodation, stigma, and marginalisation. ${ }^{8-10}$ Compared to the host country population, migrant workers use less health care and receive a lower quality of care. ${ }^{11}$ To further understand the needs of the migrant workers, their perception towards the current health system, especially in accessibility, affordability, and equity, is very much needed. It can be used as the basis to develop a new immigrant-friendly policy in the future.

Accessibility in the concept of healthcare services has many components. Accessibility does not only mean that the individual can reach and use health care services provided. Nevertheless, it evolves more on physical accessibility, availability of the health services, health care equity, the acceptability of the health care services among a specific group of people, and most importantly, the affordability of the given services. ${ }^{12-14}$ Affordability is usually equated to an individual's capacity to use health care services to the total family income. ${ }^{15,16}$ In the modern era of medicine, to serve equal service to all socioeconomic background population, various healthcare financing has been put in place to have full access to any medical treatment.

Among the migrant workers, health financing or health insurance remains a challenge. Although most employers cover their employees with basic health insurance, the benefits are still in its very minimal state. Essential treatment costs are covered, and if in need of more extensive care, the migrant workers must pay out of their own pockets. Unaffordable health care services reduce the accessibility of the migrant workers to seek for health and help. When the migrant workers have to face financial barriers to seek health care, there is no equity towards health care services. Does a successful health care provider provide equal health care services to every single individual? The success of health care services is usually assessed on the utilisation of the given services and the service users' satisfaction level. ${ }^{17,18}$ As migration is a global phenomenon, and in most cases, the migratory phenomenon was examined from historical, social, economic, and cultural perspectives. ${ }^{19}$ However, health and healthcare perspectives are mostly understudied. Thus, the present study aimed to determine the perceived knowledge of current health care delivery in Malaysia by foreign workers.

\section{MATERIALS AND METHODS}

\section{Setting and sampling}

We collected data from the Bangladeshi workers in Kuching Division, Sarawak, Malaysia, in a cross-sectional study design. Their views on health care delivery in Malaysia were assessed. We included the men aged 18 years and above living in their current residence as a sample. The calculated sample size was 401 , based on the prevalence of morbidity ${ }^{10}$. Only 314 workers managed to be interviewed. The overall response rate was $87.2 \%$. In Sarawak, the foreign workers come mainly from Indonesia, Myanmar, Bangladesh, Pakistan etc. This study particularly includes only one country's workers; if we include many country workers in this study, there might be a possibility of bias in analysis from different perspectives like cultural issues, etc.

\section{Data collection}

Data collection instrument was adapted and modified based on previous studies ${ }^{20,21}$. The instrument consists of a sociodemographic profile, morbidity, health-seeking behaviour, perceived health care delivery, and acculturation process in the destination country. The instrument was pre-tested in a non-sample area for reliability, consistency, and comprehensibility. However, the respondents who participated in the pre-test were not included in the main survey. A minor change was made after the pilot test. Initially, the instrument was developed into English, and the content analysis was done and was translated into Bangla (mother tongue of the workers). For consistency of the questions, back-to-translation was done. The interview was done in the worker's residence. Data collection was done at the weekend. A Bengali speaking university student was appointed for data collection and was collected via face-to-face interview. The research leader time to time verified the data for accuracy and consistency. Every time a field note was taken after an informal discussion with the workers. Ethical approval was obtained from the Faculty of Medicine and Health Sciences, Universiti Malaysia Sarawak (Ref: UNIMAS/NC-21.02/03-02 (13)).

\section{Measurements}

We analysed Malaysia's perceived health care delivery system in three domains: viz. accessibility, affordability, and equity in health care. Each domain was measured using 5 points Likert's scale.

Perceived accessibility of health services was measured by eight items of questions with a Likert scale ranging from very difficult to very easy. A composite mean score was calculated based on eight items and converted into a percentage for straightforward interpretation,

Perceived affordability of health care was measured by six items of questions that were asked and scored the same as the domain accessibility. The Likert scale of each item ranged from strongly disagree to strongly agree. A high score indicated affordable health care. The affordability of health care was mostly on price, insurance coverage, and subsidy on medicine as a foreign worker. ${ }^{20,21}$ 
The equity of health care was measured by five items of questions. Each item was measured on a Likert scale based on strongly disagree to strongly agree. A high score indicated equitable service.

The acculturation process was measured by three domains such as language, cultural behaviour, and knowledge. The complex social-psychological context in which the acculturative process occurs in a different environment was the main idea. ${ }^{22}$ A total of 22 items with Likert's scale of questions were asked to assess the cultural adaptation.

\section{Data entry and analysis}

Any incomplete data with more than $25 \%$ non-response after each session were discarded. IBM SPSS version 22.0 was used for data analysis. ${ }^{23} \mathrm{~A}$ descriptive analysis was done after cross-checking and validation of the data set. To determine the factors affecting each domain's perceived health care delivery, stepwise forward inclusion, and backward elimination multiple linear regression analysis was done. Finally, another multiple linear regression was also done with a composite score of perceived health care delivery as the dependent variable. The qualitative variables were dummy coded before being fitted into the regression model. A p-value of $\leq 0.05$ is considered statistically significant.

\section{RESULTS}

\section{Socio-demographic profile}

Most of the migrant workers were young adults with an average age of $35.9(\mathrm{SD}=7.3)$ years. Nearly a hundred per cent were Muslims (98.1\%) and married (84.7\%). More than two-fifths (43.3\%) had a secondary, followed by the primary level of education (33.8\%). However, $15.6 \%$ had no formal education. Manufacturing (43\%) appeared to be the highest job category, followed by construction (32.2\%), and multiple jobs according to the employer's desire $(22.9 \%)$. The majority of the workers $(82.2 \%)$ get a daily wage, and the rest get a monthly wage. The average income was MYR 923.0 per month. On average, four members were dependent on the worker's income. The average duration of working in Malaysia was ten years. The majority of the workers $(84.1 \%)$ were living in a shared room. About two-thirds (63.4\%) had health insurance, and the rest had none (Table 1).

Table 1: Socio-demographic profile

\begin{tabular}{lll} 
Characteristics & Frequency & $\begin{array}{l}\text { Percent / } \\
\text { Mean }\end{array}$ \\
\hline $\begin{array}{l}\text { Age (Mean, SD) years } \\
\text { Religion }\end{array}$ & 314 & $35 \cdot 9(7 \cdot 3)$ \\
Islam & 308 & 98.1 \\
Hinduism & 6 & 1.9
\end{tabular}

Table 1: (Continued)

\begin{tabular}{|c|c|c|}
\hline Characteristics & Frequency & $\begin{array}{l}\text { Percent / } \\
\text { Mean }\end{array}$ \\
\hline \multicolumn{3}{|l|}{ Marital status } \\
\hline Single & 48 & $15 \cdot 3$ \\
\hline Married & 266 & $84 \cdot 7$ \\
\hline \multicolumn{3}{|l|}{ Education } \\
\hline No education & 49 & 15.6 \\
\hline Primary & 106 & 33.8 \\
\hline Secondary & 136 & $43 \cdot 3$ \\
\hline Higher secondary & 23 & $7 \cdot 3$ \\
\hline \multicolumn{3}{|l|}{ Nature of job } \\
\hline Farming & 6 & 1.9 \\
\hline Construction & 101 & 32.2 \\
\hline Manufacturing & 135 & 43.0 \\
\hline Others & 72 & 22.9 \\
\hline \multicolumn{3}{|l|}{ Type of payment } \\
\hline Daily wage & 258 & 82.2 \\
\hline Monthly wage & 56 & 17.8 \\
\hline $\begin{array}{l}\text { The average income per month } \\
\text { (RM) }\end{array}$ & 314 & 923.0 \\
\hline Average dependants & 314 & 4.0 \\
\hline $\begin{array}{l}\text { Work experience in Malaysia } \\
\text { (yrs) }\end{array}$ & 314 & 10.0 \\
\hline \multicolumn{3}{|c|}{ Working experience in other countries } \\
\hline Yes & 17 & $5 \cdot 4$ \\
\hline No & 297 & 94.6 \\
\hline \multicolumn{3}{|l|}{ Living environment } \\
\hline Shared room & 264 & 84.1 \\
\hline Single room & 50 & $15 \cdot 9$ \\
\hline \multicolumn{3}{|l|}{ Ever take sick leave } \\
\hline Yes & 58 & 18.5 \\
\hline No & 256 & 81.5 \\
\hline \multicolumn{3}{|l|}{ Having health insurance } \\
\hline Yes & 199 & 63.4 \\
\hline No & 80 & $25 \cdot 5$ \\
\hline No idea & 35 & 11.1 \\
\hline \multicolumn{3}{|c|}{ Bearing treatment cost by employer } \\
\hline Never & 115 & 36.6 \\
\hline Partial & 129 & 41.1 \\
\hline All types of cost & 70 & 22.3 \\
\hline
\end{tabular}

\section{Perceived health care services}

The analysis revealed that the highest score was in accessibility with a mean (SD) 91.4 (8.95) per cent, followed by the equity in health care with a mean (SD) 87.2 (9.7) per cent. The lowest score was in the affordability of health care 
with a mean (SD) 78.2 (12.9) per cent. The overall mean (SD) score of perceived health care was 86.0 (6.3) per cent (Figure 1).



Figure 1: Mean percentage distribution of perceived health care services in Malaysia

\section{Factors affecting the perceived health care services}

A stepwise with forwarding inclusion and backward elimination multiple linear regression analysis was performed to determine the predictors for perceived health care in Malaysia. Table 2 presents the stepwise-regression analysis with the Adjusted $\mathrm{R}^{2}$ and $\mathrm{F}$ ratio. The qualitative variables were dummy coded with ' 0 ' and ' 1 ' to fit the model.

The analysis revealed that payment on a daily wage appeared to be positively correlated with the accessibility of health care. However, manufacturing and farming job, single status, and secondary level of education were negatively correlated with healthcare accessibility $(p<.05)$. On the other hand, workers with health insurance were very strongly positively correlated with health care affordability $(p<.001)$. The workers without health insurance were weakly positively correlated with healthcare affordability $(p<.05)$. Nevertheless, the cultural adaption was negatively correlated with the affordability of health care $(\mathrm{p}<.001)$. The analysis revealed that the workers with a daily wage basis $(\mathrm{p}<.001)$ and construction jobs $(\mathrm{p}<.01)$ were strongly positively correlated with equity of health care. However, workers aged 50 years and above $(p<.001)$, monthly income less than MYR $900(\mathrm{p}<.001)$ were negatively correlated with equity of health care $(\mathrm{p}<.05)$. Analysis of total score showed that daily wage $(\mathrm{p}<.001)$, monthly income MYR 900-1300 $(\mathrm{p}<.001)$, and income MYR 1300 and above $(\mathrm{p}<.001)$ were strongly positively correlated with perceived health care. However, manufacturing jobs, no idea about the health insurance, and adaptation of local culture were negatively correlated with perceived health care $(\mathrm{p}<0.05)$ (Table 2).

Table 2: Factors affecting the perceived health care services in Malaysia: Stepwise Multiple linear regression

\begin{tabular}{|c|c|c|c|c|}
\hline Variables & $\begin{array}{c}\text { Accessibility } \\
(\beta)\end{array}$ & $\begin{array}{c}\text { Affordability } \\
(\beta)\end{array}$ & $\begin{array}{l}\text { Equity } \\
(\boldsymbol{\beta})\end{array}$ & $\begin{array}{c}\text { Total } \\
(\beta)\end{array}$ \\
\hline Age $\geq 50$ years & - & - & $-.363^{* * *}$ & - \\
\hline Payment on daily basis & $.230^{* * *}$ & - & $.302^{* * *}$ & $.195^{* * *}$ \\
\hline Manufacturing job & $-.176^{* * *}$ & - & -.118 & $-.143^{* * *}$ \\
\hline Farming job & $-.424^{*}$ & - & - & - \\
\hline Construction workers & - & - & $.195^{* *}$ & - \\
\hline Secondary education & $-.112^{*}$ & - & - & - \\
\hline Marital status by single & $-.204^{*}$ & - & - & - \\
\hline Income $<$ MYR 90o.oo & - & - & $-.26 \mathrm{o}^{* * *}$ & - \\
\hline Income MYR 90o.oo - 1299.99 & - & - & - & $.126^{* * *}$ \\
\hline Income $\geq$ MYRizoo.oo & & & & $.169^{* * *}$ \\
\hline Having health insurance & - & $.507^{* * *}$ & - & - \\
\hline No health insurance & - & $.276^{*}$ & - & - \\
\hline No idea about health insurance & - & - & - & $-.167^{* *}$ \\
\hline Adaptation of local culture & - & $-.026^{* * *}$ & - & $-.016^{* * *}$ \\
\hline Constant & 4.543 & 4.395 & 4.253 & 4.684 \\
\hline Adj. $R^{2}$ & 0.147 & 0.164 & 0.212 & 0.340 \\
\hline$F(d f)$ & $9.964(6,307)$ & $21.507(3,310)$ & $11.544(8,305)$ & $15.649(11,302)$ \\
\hline$N$ & 314 & 314 & 314 & 314 \\
\hline
\end{tabular}

Adj. $\mathrm{R}^{2}=$ Adjusted R-Squared; ${ }^{*} \mathrm{p}<.05 ;{ }^{* *} \mathrm{p}<.01 ;{ }^{* *} \mathrm{p}<.001$ 


\section{DISCUSSION}

From the socio-demographic point of view, most of the respondents are working-aged adults and of Muslim faith, as Bangladesh is a Muslim-predominant country. About half of them have at least a secondary level of education, which was explained why most respondents are working in manufacturing and construction jobs. ${ }^{24}$ With the median salary of close to MYR 1000 per month and the number of dependents is about four members, most of the respondents lived in a shared room to reduce their expenditure. The average income and sharing of accommodation findings are similar to Karim et al. ${ }^{24}$ consisting of a room of about 200 sq. feet. The majority have no or minimum ventilation and shared by five workers. Most of the workers experienced working in Malaysia for about ten years, although almost all of them did not have experience working in any other country before. This could be due to bilateral agreements since 1992 between both governments, resulting in many migrant workers from Bangladesh coming to Malaysia. ${ }^{24}$ This also shows that Malaysia is one of the preferred destinations for workers from Bangladesh, who probably could not find a job in their country of origin. Regarding the health insurance and treatment cost bearer, the majority of them are already covered. This might be due to their better knowledge and awareness concerning their health and well-being. On the contrary, most Bangladeshi workers in Singapore did not know their insurance policy coverage. ${ }^{25}$

The results showed that the mean distributions for accessibility had the highest score in the perceived health care services domain. This proves that health care services are easily accessible as the government clinics are placed in strategic areas. According to Noh et al. ${ }^{2}$ a good number of foreign workers also visited the private sector for the treatment of their illnesses. The delivery of services is also impartial and unbiased to foreign workers. The lowest was affordability and equitability. However, as similarly found in another study by Noh et al. ${ }^{2}$ the price of health services was considered expensive. This is likely due to the recently implemented Akta Fi or Fee Charges Act for all foreign patients attending government health providers. The workers mentioned:

".... we believe that the health care service is good, but not affordable to us, because of new fees imposed by the government".

\section{Manufacturing worker, Kuching}

Factors affecting the perceived health care services and potential predictors for perceived health care in Malaysia were determined using stepwise multiple linear regression analysis. It was found that accessibility of health care was positively correlated with daily wage salary but negatively correlated with being single, the secondary level of education, and manufacturing and farming jobs. The workers are likely to be able to afford health care services if they have an insurance policy compared to those without one. It was negatively correlated to those who failed to adapt culturally to the country they are working in. According to Karim \& Diah ${ }^{24}$, most of the Bangladeshi workers found it challenging due to unfamiliarity with Malaysia's health care services. However, one worker mentioned that..

"...I do not feel any discomfort with the doctor's behaviour and communication, though we are foreigners, we are accustomed to the local language. The doctor and even medicine dispenser nicely described how to use the medicine and necessary follow-up action".

\section{Agriculture worker, Bau}

Equity of healthcare was positively correlated to the construction workers and those who are being paid on a daily wage but negatively correlated to those aged 50 years and above and those who have a lower income of less than MYR 900 per month. Foreign workers with middle to high income and who receive daily wages were positively correlated with perceived health care. However, poor local cultural adaptation, none or insufficient knowledge of health insurance, and working in a manufacturing job negatively correlated with perceived health care.

\section{"- as foreigners, we do not feel any discrimination, the doctor, nurse even medicine dispensers are well be- haved and accept us as a patient like locals."}

\section{Factory workers, Kuching}

This study has a few limitations. The total number of Bangladeshi workers who were interviewed was only 314 , a relatively small sample size. The study was also limited to only one division, which was in Kuching, Sarawak. The results may not be representative of all Bangladeshi workers in other states of Malaysia. Due to the nature of face-to-face interviews, the issue of recall bias may arise. The answers that were given by the respondents in this study could also be affected by the cultural differences between Malaysia and their country of origin, Bangladesh.

\section{CONCLUSIONS}

Because of the study's small scale, drawbacks, including the non-availability of the sample population and lack of generalisability, may prevail. Nevertheless, this study's findings could be used as input for creating a policy guideline for developing a health care delivery system that is approachable and friendly to migrant workers in Malaysia. Offering affordable and equitable health care for them is as important as the migrant worker's existence and contribution to the development of the country. 


\section{ACKNOWLEDGEMENTS}

We would like to thank the Institute of Borneo Studies (IBS) (Grant no. F05/(TNC)/1335/2016(1) and Research Innovation and Enterprise Centre (RIEC), (No. UNIMAS/ TNC(PI)-04.01/09-03/01 Jld 2(17), Universiti Malaysia Sarawak (UNIMS) for approval and funding the research. The authors are also grateful to authors, editors, publishers of all those articles, journals, and books from where the literature for this article has been reviewed and discussed. We are also grateful to the workers for their participation in this study.

Competing Interests: All authors declare that they had no competing interests.

Funding: The research received a grant from the Institute of Borneo Studies (IBS), Nusantara Chair, Universiti Malaysia Sarawak from the (Ref: F05/(NRC)/1335/2016(1). The funders had no role in any part of the research.

Author's Contribution: Concept, design, analysis, and interpretation, drafting manuscript: Rahman MM, Data collection: Arif, MT, Jantan Z, Akoi P., Safii R. Manuscript drafting: Rahman MM, Kaliaperumal, Ridzuan S. Manuscript editing: Rahman MM, Arif MT, Tambi Z. All authors approved the final manuscript for publication.

\section{REFERENCES}

1. Tahir NAM, Li SC, Thomas P. Challenges and Opportunities in the Malaysian Health Care System. Value Health 2014;17(7):A802.

2. Noh NA, Wahab HAbd, Bakar Ah SHA, Islam MR. Public Health Services for Foreign Workers in Malaysia. Soc Work Public Health. 2016;31(5):419-430.

3. Quek DK. The Malaysian Health Care System: A Review. In: Women's Development Research Centre; 2009.

4. MOH, Malaysia. Annual Report 2003. Ministry of Health, Malaysia; 2003. http://www.moh.gov.my/images/gallery/publications/md/ar/2003-1.pdf

5. Laws of Malaysia. Private Healthcare Facilities and Services Act 1998; 2006. http://www.agc.gov.my/agcportal/uploads/ files/Publications/LOM/EN/Act\%20586.pdf

6. Thomas S, Beh L, Nordin RB. Health Care Delivery in Malaysia: Changes, Challenges and Champions. J Publ Heal Afr 2011;2(2).

7. Flaskerud JH, Winslow BJ. Conceptualizing Vulnerable Populations Health-Related Research. Nurs Res 1998;47(2):69-78.

8. Lauderdale DS, Wen M, Jacobs EA, Kandula NR. Immigrant Perceptions of Discrimination in Health Care: The California Health Interview Survey 2003. Med Care 2006;44(10):914-920.
9. Mays GP, McHugh MC, Shim K, et al. Institutional and Economic Determinants of Public Health System Performance. Am J Publ Heal 2006;96(3):523-531.

10. Peng Y, Chang W, Zhou H, Hu H, Liang W. Factors Associated with Health-Seeking Behavior Among Migrant Workers in Beijing, China. Heal Serv Res 2010;10:69.

11. Shah NS, Carrasquillo O. Twelve-Year Trends in Health Insurance Coverage Among Latinos, By Subgroup and Immigration Status. Health Aff Mill 2006;25(6):1612-1619.

12. Blais R, Maïga A. Do Ethnic Groups Use Health Services Like the Majority of the Population? A Study from Quebec, Canada. Soc Sci Med 1999;48(9):1237-1245.

13. Gonzo Wafula E, Snipes S. Barriers to Health Care Access Faced by Black Immigrants in the US: Theoretical Considerations and Recommendations. J Immigr Minor Health Cent Minor Pub Heal 2013;16(1):349-351.

14. Liu CH, Ingleby D, Meeuwesen L. Barriers to Health Care for Chinese in the Netherlands. Int J Fam Med 2011;2(5):341-345.

15. Nielsen SS, Hempler NF, Waldorff FB, Kreiner S, Krasnik A. Is There Equity in Use of Healthcare Services Among Immigrants, Their Descendents, and Ethnic Danes? Sca J Pub Heal 2012;40(3):260-270.

16. Peters DH, Garg A, Bloom G, Walker DG, Brieger WR, Rahman MH. Poverty and Access to Health Care in Developing Countries. Ann N Acad Sci 2008;1136:161-171.

17. McFall DC, Yoder LH. Critical Access Health Care: A Concept Analysis. Nurs Forum 2012;47(1):9-17.

18. Norris TL, Aiken M. Personal Access to Health Care: A Concept Analysis. Public Health Nurs Boston Mass 2006;23(1):59-66.

19. Marceca M, ed. Migration and Health from a Public Health Perspective. In: People's Movements in the 21st Century - Risks, Challenges and Benefits. In Tech Open. 2017:5(3):103-127.

20. Rahman MM, Shahidullah M, Shahiduzzaman M, Rashid HA. Quality of Health Care from Patient Perspectives. Bangladesh Med Res Counc Bull 2002;28(3):87-96.

21. Thanavanh B, Rashid MHO, Kasuya H, Sakamoto J. Knowledge, Attitudes and Practices Regarding Hiv/Aids Among Male High School Students in Lao People's Democratic Republic. J Int AIDS Soc 2013;16(5):17387.

22. Drankus D. Indicators of Acculturation: A Bilinear, Multidimensional Approach. Advoc Forum 2010:35-49. Accessed May 3, 2018. http://ssa.uchicago.edu/indicators-acculturation-bilinearmultidimensional-approach

23. IBM SPSS. IBM SPSS Statistics for Windows. IBM SPSS; 2013.

24. Karim AZ, Diah NM. Health Seeking Behavior of the Bangladeshi Migrant Workers in Malaysia: Some Suggestive Recommendations in Adjustive Context. Asian Soc Sci 2015;11(10):348-357.

25. Ang JW, Chia C, Koh CJ, et al. Healthcare-Seeking Behaviour, Barriers and Mental Health of Non-Domestic Migrant Workers in Singapore. BMJ Glob Health 2017;2(2):e000213. 